\title{
Association between depression, glycaemic control and the prevalence of diabetic retinopathy in a diabetic population in Cameroon
}

\begin{tabular}{|c|c|}
\hline $\begin{array}{l}\text { Authors: } \\
\text { Kirsty K. Hall } \\
\text { Joelle Tambek }^{1} \\
\text { Linda Penn }{ }^{1} \\
\text { Alioune Cama } \\
\text { Naby M. Bald } \\
\text { Eugene Sobng }\end{array}$ & $\begin{array}{l}u^{2} \\
w^{3} \\
{ }^{3}\end{array}$ \\
\hline $\begin{array}{l}\text { Society, Newcastle University, } \\
\text { United Kingdom }\end{array}$ & $\begin{array}{l}\text { ealth and } \\
\text { astle University, } \\
\text { m }\end{array}$ \\
\hline \multicolumn{2}{|c|}{$\begin{array}{l}{ }^{2} \text { Catholic University of Central } \\
\text { Africa, Cameroon }\end{array}$} \\
\hline \multicolumn{2}{|c|}{$\begin{array}{l}{ }^{3} \text { Department of } \\
\text { Endocrinology, University } \\
\text { Hospital, Guinea }\end{array}$} \\
\hline \multicolumn{2}{|c|}{$\begin{array}{l}\text { Corresponding author: } \\
\text { Kirsty Hall, } \\
\text { kirstykhall@doctors.org.uk }\end{array}$} \\
\hline \multicolumn{2}{|c|}{$\begin{array}{l}\text { Received: } 10 \text { Mar. } 2016 \\
\text { Accepted: } 30 \text { Mar. } 2017 \\
\text { Published: } 01 \text { June } 2017\end{array}$} \\
\hline \multicolumn{2}{|c|}{$\begin{array}{l}\text { How to cite this article: } \\
\text { Hall KK, Tambekou J, Penn L, } \\
\text { Camara A, Balde NM, } \\
\text { Sobngwi E. Association } \\
\text { between depression, } \\
\text { glycaemic control and the } \\
\text { prevalence of diabetic } \\
\text { retinopathy in a diabetic } \\
\text { population in Cameroon. } \\
\text { S Afr J Psychiat. 2017;23(0), } \\
\text { a983. https://doi.org/ } \\
\text { 10.4102/sajpsychiatry. } \\
\text { v23i0.983 }\end{array}$} \\
\hline \multicolumn{2}{|c|}{$\begin{array}{l}\text { Copyright: } \\
\text { (C) 2017. The Authors. } \\
\text { Licensee: AOSIS. This wo } \\
\text { is licensed under the } \\
\text { Creative Commons } \\
\text { Attribution License. }\end{array}$} \\
\hline \multicolumn{2}{|l|}{ Read online: } \\
\hline 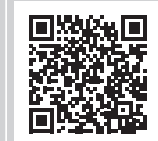 & $\begin{array}{l}\text { Scan this QR } \\
\text { code with your } \\
\text { smart phone or } \\
\text { mobile device } \\
\text { to read online. }\end{array}$ \\
\hline
\end{tabular}

Purpose: The prevalence of diabetes mellitus is increasing especially in low- and middleincome countries in which $75 \%$ of the world's diabetic population reside. The macro- and microvascular complications of diabetes such as diabetic retinopathy are also set to increase in these populations.

The relationship between depression and glycaemic control has been established in highincome countries, but evidence from low- and middle-income countries is scarce. This research aimed to determine an association between depression and glycaemic control and record the prevalence of diabetic retinopathy in a diabetic population in Cameroon.

Methods: Analysis of cross-sectional data from the 'Improving access to $\mathrm{HbA} 1 \mathrm{c}$ measurements in sub-Saharan Africa' study was used. Primary data were collected from six diabetic care facilities in Yaoundé, Cameroon. Participants were aged $\geq 18$ years with at least a 6-month history of diabetes. Depression was assessed using the Centre for Epidemiological Studies Depression Scale (CES-D). A CES-D score $\geq 16$ was used to identify the presence of clinically significant depressive symptoms. Data on glycaemic control were measured using HbA1c measurements at baseline. The presence of diabetic retinopathy was established through ophthalmoscopy and angiography using the Early Treatment Diabetic Retinopathy Study classification.

Results: A total of 261 participants were included in the study, and information on depressive symptoms at baseline (CES-D score) were available for 240 participants. The results of the data analysis found that $60 \%$ of the study participants had clinically significant depressive symptoms (CES-D > 16). A weak non-significant positive correlation was found between CES-D score and HbA1c level ( $p=0.46, r=0.05)$ using the Pearson's correlation co-efficient. Gender and attendance to a patient support group were significantly associated with the presence of clinically significant depressive symptoms. Poor glycaemic control ( $\mathrm{HbA} 1 \mathrm{c}>7 \%)$ was found in $72.8 \%$ of the population. Educational level and insulin use were significantly associated with glycaemic control.

The prevalence of diabetic retinopathy was $27.2 \%$ (23.4\% non-proliferative, $2.5 \%$ preproliferative and $3.2 \%$ proliferative), and the prevalence of diabetic maculopathy was $10.0 \%$.

Conclusion: The study found that a large proportion of diabetic patients may be experiencing depressive symptoms for which they are currently not receiving treatment or support. We also found a large proportion to have poor glycaemic control that is known to worsen the vascular complications of diabetes. In light of the increasing epidemic of type 2 diabetes in sub-Saharan Africa, it is important that the recognition of depressive symptoms becomes integrated into future healthcare policies in the nations of sub-Saharan Africa. This research suggests that individuals experiencing depressive symptoms may be more likely to engage in patient support groups. These groups can be beneficial in providing patients with diabetes valuable information, which could lead to better glycaemic control.

\section{Introduction}

Diabetes mellitus is currently one of the most important public health issues of the 21st century affecting an estimated 347 million people worldwide with low- and middle-income countries currently being home to $75 \%$ of the world's diabetic population. ${ }^{1}$ Sub-Saharan Africa is currently facing an epidemic of type 2 diabetes mellitus, thought to have arisen because of rapid urbanisation, an increasingly ageing population and major changes in lifestyle. ${ }^{2,3}$ 
Depression is the leading cause of disability worldwide and is a major contributor to the global burden of disease, affecting an estimated 350 million people. ${ }^{4}$ Research has shown depression to be associated with a high mortality in people with diabetes. ${ }^{5,6,7,8}$ Patients with diabetes are twice as likely to be depressed compared to those without diabetes. ${ }^{9}$ Alongside this, depression can also lead to an increased risk of the vascular complications of diabetes such as diabetic retinopathy, neuropathy and cardiovascular disease..$^{10}$

Diabetic retinopathy is a microvascular complication of diabetes and is the leading cause of blindness in people of working age in Europe and North America. ${ }^{11}$ In sub-Saharan Africa, the prevalence of retinopathy in patients with diabetes varies across the continent ranging from 16 in some regions to $55 \%$ in other regions. ${ }^{2}$ Estimates of prevalence vary according to duration, clinical site and glycaemic control. The contribution to overall blindness in sub-Saharan Africa is unknown, but studies suggest that the proportional contribution may be increasing. ${ }^{2}$ Studies to date involving multiethnic populations living in sub-Saharan Africa have found that visual loss relating to diabetic retinopathy is more likely in populations of African origin compared to those of other ethnic minorities living in sub-Saharan Africa. ${ }^{12}$

Literature on depression in people residing in low- and middle-income countries is limited but growing evidence demonstrates the negative impact of poverty and mental health illness on people living in these regions. ${ }^{13}$ Much of the research surrounding depression and type 2 diabetes that has been conducted in low- and middle-income countries have primarily been conducted in middle-income economies such as India, China, Mexico and Brazil. ${ }^{14}$

Over the past 50 years, there has been an increased awareness of depression in sub-Saharan Africa. ${ }^{15}$ Prior to this, depression was assumed to be non-existent in Africa, and even today, the prevalence may still be underestimated. ${ }^{16,17}$ However, information about depressive symptoms in individuals living with chronic illnesses in sub-Saharan Africa is still scarce.$^{18}$ Despite this, research from low-income economies such as Bangladesh and Guinea suggests that anxiety and depressive symptoms are common in patients living with diabetes. ${ }^{19,20}$

The aim of this research was to analyse the association between depressive symptoms and glycaemic control and record the prevalence of diabetic retinopathy in a clinical sample of patients with diabetes from the 'Improving access to $\mathrm{HbA1c}$ measurement in sub-Saharan Africa' project. $^{21}$

\section{Materials and methods}

Data were collected from a multicentre hospital cohort involving six diabetic care facilities in Yaoundé, Cameroon. This study was performed as secondary data analysis of the 'Improving access to $\mathrm{HbA} 1 \mathrm{c}$ measurement in sub-Saharan Africa' study. ${ }^{22}$ The empirical study was an interventional study aiming to improve access to $\mathrm{HbA1c}$ measurements in
sub-Saharan Africa. The empirical research was conducted from 01 November 2008 to 30 April 2012 in Guinea and Cameroon involving a total of 410 diabetic adult patients with both type 1 and type 2 diabetes mellitus and had a $97 \%$ response rate.

Secondary data were analysed from a total of 261 of the 410 participants who had $\mathrm{HbA} 1 \mathrm{c}$ scores recorded at baseline. The study included participants aged 18 years and older who had at least a 6-month documented history of diabetes. Patients who had been diagnosed for less than 6 months and those with other acute medical or metabolic conditions were excluded from the study.

Primary data were collected through a semistructured questionnaire. The questionnaire was administered by either a nurse or another healthcare professional and contained anonymised information on $\mathrm{HbA} 1 \mathrm{c}$ control, socio-demographic characteristics and diabetes-related characteristics and risk factors for diabetes. Data on the presence of diabetic retinopathy and depressive symptoms at baseline were also collected.

The socio-demographic data included age, gender, employment status, marital status and educational level. Educational level was divided into those who had achieved primary education or less (including those with no formal education) and those who had achieved secondary education and higher. Diabetes-related characteristics such as hypertension, obesity, insulin use and glycaemic control were included. Involvement in physical activity and patient support groups were also included. Obesity was measured according to the World Health Organisation classification for adult obesity with a body mass index $(\mathrm{BMI})>30 \mathrm{~kg} / \mathrm{m}^{2}$ used to define obesity. Information on glycaemic control was obtained through $\mathrm{HbA} 1 \mathrm{c}$ measurements. This analysis used anonymised information about $\mathrm{HbA} 1 \mathrm{c}$ readings taken in a clinic by a trained physician at baseline.

The presence of diabetic retinopathy was detected through the use of a clinical eye examination, fundoscopy and fluorescein angiography. All cases of retinopathy were detected by an ophthalmologist using retinal photographs. Diabetic retinopathy was classified as absent, nonproliferative, pre-proliferative and proliferative according to the Early Treatment Diabetic Retinopathy Study classification. ${ }^{23}$ The presence of diabetic maculopathy was diagnosed through fundal examination.

Information on depressive symptoms at baseline was assessed through the use of the Centre for Epidemiological Studies Depression Scale (CES-D). The CES-D scale was created by Laurie Radloff in 1977 as a self-administered questionnaire to assess current levels of depressive symptoms in the general population. ${ }^{24}$ Questions for the scale are drawn from other inventories including the Beck Depression Inventory, Zung Self-Rating depression Scale and the Raskin Scale. However, the CES-D scale differs from previous depression scales because of its focus on identifying 
depressive symptomology in the general population rather than diagnosing depression in a clinical setting. ${ }^{24}$

The CES-D scale was originally designed to screen for depressive symptomology in North American populations; however, it has since been used widely in a variety of subSaharan nations such as Uganda, Zambia, Nigeria and Senegal and validated in South Africa, Zambia, Uganda and Nigeria. 25,26,27,28,29 The 20-item questionnaire centres on the major clinical symptoms of depression. Answers are given on a score of $0-3$ relating to the frequency of symptoms experienced during the past week. The possible scores range from 0 to 60 with high scores indicating more depressive symptoms. A recommended score of greater than 16 is usually recommended to suggest the presence of clinically meaningful depressive symptoms. In this study, individuals with CES-D scores $>16$ were identified as having clinically significant depressive symptoms.

\section{Statistical analysis}

The original data were obtained within the SPSS statistics 19 package..$^{30}$ Analysis was made using the Minitab 16 and Epi Info $^{\text {TM }} 7$ statistical software. ${ }^{31,32}$ Categorical variables were analysed using chi-squared test or Fisher's exact tests if the expected cell counts were less than 5. Assessment for effect modification and confounding was conducted.

\section{Ethical considerations}

The National Ethics Committee in Cameroon approved the study. Participants involved in the study gave written informed consent to voluntarily participate in the study and permission to use information for the purpose of secondary data analysis. We certify that all applicable institutional and governmental regulations concerning the ethical use of human volunteers were followed during this research. This research adhered to the Declaration of Helsinki and was reviewed by the Institutional Review Board at Newcastle University.

\section{Results}

A total of 261 individuals were included in the secondary analysis for which $\mathrm{HbA1c}$ was recorded at baseline. A total of 240 of these participants had depressive symptoms (CES-D scores) recorded at baseline. The general characteristics included in the study are presented in Table 1. Missing variables were noted and the categorical variables for which there were incomplete data sets were not included in the statistical analysis (see Tables 3 and 4).

The study had a female majority (56.3\%) with a mean age was 56 years and a standard deviation (SD) of 12.21. The age data followed an approximately normal distribution, with an age range of $16-85$.

Most individuals had secondary education or higher (57.1\%), and $42.9 \%$ had primary education or less. The majority of the sample population were married (65.9\%) and 34.1\% were classified as single with just over half of the population (55.1\%) identifying as either retired or unemployed.

The majority of participants (92.7\%) were reported as having type 2 diabetes mellitus (see Table 2). Just over half of the study participants $(57.0 \%)$ had diabetes for $\geq 5$ years, $31.1 \%$ of the population were defined as obese and $57.0 \%$ of

TABLE 1: Baseline demographics for diabetes-related characteristics in a sample population.

\begin{tabular}{lc}
\hline Characteristics $(\boldsymbol{n}=\mathbf{2 6 1})$ & Number (\%) \\
\hline Sex & $114(43.7)$ \\
Male & $147(56.3)$ \\
Female & \\
Marital status & $170(65.9)$ \\
$\quad$ Married & $88(34.1)$ \\
$\quad$ Single & \\
Educational level & $112(42.9)$ \\
Primary or less & $149(57.1)$ \\
Secondary or higher & \\
Employment & $117(44.9)$ \\
Employed & $144(55.1)$ \\
Unemployed & \\
Alcohol consumption & $62(32.1)$ \\
Yes & $131(67.9)$ \\
$\quad$ No &
\end{tabular}

TABLE 2: Diabetes-related categorical characteristics in the study population.

\begin{tabular}{|c|c|}
\hline Diabetes-related characteristics ( $n=261)$ & Number (\%) \\
\hline \multicolumn{2}{|l|}{ Type } \\
\hline 1 & $16(6.1)$ \\
\hline 2 & $242(92.7)$ \\
\hline Other & $3(1.6)$ \\
\hline \multicolumn{2}{|l|}{ Duration } \\
\hline$<5$ years & $110(43.0)$ \\
\hline$\geq 5$ years & $146(57.0)$ \\
\hline \multicolumn{2}{|l|}{ Obesity } \\
\hline Yes & $79(31.1)$ \\
\hline No & $175(68.9)$ \\
\hline \multicolumn{2}{|l|}{ HbA1c (\%) } \\
\hline Good control $(<7 \%)$ & $71(27.2)$ \\
\hline Poor control (> 7\%) & $190(72.8)$ \\
\hline \multicolumn{2}{|l|}{ Hypertension } \\
\hline Yes & $135(57.0)$ \\
\hline No & $102(43.0)$ \\
\hline \multicolumn{2}{|l|}{ Insulin } \\
\hline Yes & $96(36.8)$ \\
\hline No & $165(63.2)$ \\
\hline \multicolumn{2}{|l|}{ Patient support group } \\
\hline Yes & $53(20.3)$ \\
\hline No & $208(79.7)$ \\
\hline \multicolumn{2}{|l|}{ Physical activity } \\
\hline Yes & $62(27.7)$ \\
\hline No & $162(72.3)$ \\
\hline \multicolumn{2}{|l|}{ Retinopathy } \\
\hline Absent & $115(72.8)$ \\
\hline Non-proliferative & $34(23.4)$ \\
\hline Pre-proliferative & $4(2.5)$ \\
\hline Proliferative & $5(3.2)$ \\
\hline \multicolumn{2}{|l|}{ Maculopathy } \\
\hline Yes & $13(10.0)$ \\
\hline No & $117(90.0)$ \\
\hline
\end{tabular}


participants were identified as having hypertension. Insulin use was reported in $36.8 \%$ of participants and $72.8 \%$ of the study population were identified as having poor glycaemic control (HbA1c level of $>7 \%$ ). Attendance in a patient support group for people living with diabetes was reported in $20.3 \%$.

\section{Diabetic retinopathy}

Information on diabetic retinopathy were available for 158 $(60.0 \%)$ of the 261 participants included in this study. Diabetic retinopathy was detected in approximately $25.0 \%$ of the subset for which data were available. The majority of cases were non-proliferative $(21.5 \%)$ with smaller proportions at the pre-proliferative $(2.5 \%)$ or proliferative $(3.1 \%)$ stage. The presence of maculopathy was detected in $10.0 \%$ of the population (see Table 2).

\section{Depressive symptomology}

Of the 261 participants studied, CES-D scores were available for $92.0 \%$ (240) of the population, with data missing for 23 people. For this reason, statistical analysis was only performed with baseline characteristics which had complete data sets for both CES-D score and HbA1c level (see Table 3).

A large proportion of participants had borderline depressive symptoms with CES-D scores around 15 and 16 at baseline, with scores ranging from 1 to 49 (out of a minimum score of 0 and a maximum score of 60).

Statistical significance was found between reporting of clinically significant depressive symptoms (CES-D score > 16), gender and involvement in a patient support group for diabetes.

The mean CES-D score for men was 17, compared to mean CES-D score of 20 for women. More women (69.1\%) reported significant depressive symptoms compared to men $(49.0 \%$, chi-squared $p<0.01$ ). Individuals who had a primary education or less reported more clinically significant depressive symptoms (64.0\%) compared to those with secondary education or more $(57.9 \%, p=0.33)$. Those who were unemployed reported more depressive symptoms $(62.7 \%)$ compared to those who were employed $(57.5 \%, p=$ 0.42 ). Individuals who use insulin also reported more depressive symptoms $(61.2 \%)$ compared to those who do not use insulin $(60.0 \%, p=0.86)$. Individuals involved in a patient support group were noted to have more clinically depressive symptoms $(76.0 \%)$ compared to those not involved in a patient support group $(56.3 \%, p<0.01)$.

Individuals with poor glycaemic control, $\mathrm{HbA1c}>7 \%$, were found to have more depressive symptoms (61.4\%) compared to those with good glycaemic control (HbA1c $\leq 7 \%)(57.5 \%)$. A weak positive correlation was found between CES-D score and $\mathrm{HbA} 1 \mathrm{c}$ level at baseline, but this was found not to be statistically significant $(r=0.05, p=0.46)$.

\section{Glycaemic control}

The majority of participants in the study (72.8\%) were identified as having poor glycaemic control (HbA1c > 7\%) at baseline. The median HbA1c score was slightly lower in women $(8.0 \%)$ compared to men $(9.0 \%)$. A significant association was found between educational level, insulin use and poor glycaemic control. A greater proportion of people with a higher educational level (12.0\%) had poor glycaemic control compared to those with less education (chi-squared $p=0.04)$. A higher proportion $(20.0 \%)$ of individuals on insulin had poor glycaemic control compared to those not using insulin (chi-squared $p<0.01$ ). Men had worse glycaemic control $(77.2 \%)$ compared to women $(69.4 \%, p=0.15)$. Those who were employed were identified as having poorer glycaemic control $(77.8 \%)$ compared to those who were unemployed $(68.7 \%, p=0.10)$ and those who did not attend a

TABLE 3: Baseline characteristics of study population analysed against Centre for Epidemiological Studies Depression Scale (CES-D) score.

\begin{tabular}{|c|c|c|c|c|c|c|}
\hline \multirow{2}{*}{$\begin{array}{l}\text { Categorical grouping } \\
\text { variables }\end{array}$} & \multicolumn{2}{|c|}{ CES-D score } & \multicolumn{4}{|c|}{ Proportion of individuals reporting depressive symptoms (CES-D > 16) } \\
\hline & Total $(N=240)$ & Mean (s.d.) & Yes $(\%)$ & No (\%) & $95 \% \mathrm{Cl}$ & $p$ \\
\hline \multicolumn{7}{|l|}{ Sex } \\
\hline Female & 136 & $20.2(7.7)$ & $94(69.1)$ & $42(30.9)$ & \multirow{2}{*}{-0.32 to -0.07} & \multirow{2}{*}{$<0.01$} \\
\hline Male & 104 & $17.1(7.7)$ & $51(49.0)$ & $53(51.0)$ & & \\
\hline \multicolumn{7}{|l|}{ Educational level } \\
\hline Primary or less & 100 & $19.7(7.7)$ & $64(64.0)$ & $36(36.0)$ & \multirow{2}{*}{-0.19 to 0.06} & \multirow{2}{*}{0.33} \\
\hline Secondary or more & 140 & $18.3(8.0)$ & 81 (57.9) & $59(42.1)$ & & \\
\hline \multicolumn{7}{|l|}{ Employment status } \\
\hline Employed & 106 & $19.2(8.5)$ & $61(57.5)$ & 45 (42.5) & \multirow{2}{*}{-0.07 to 0.17} & \multirow{2}{*}{0.42} \\
\hline Unemployed & 134 & $18.6(7.3)$ & $84(62.7)$ & $50(37.3)$ & & \\
\hline \multicolumn{7}{|l|}{ Insulin use } \\
\hline Yes & 85 & $20.1(8.5)$ & $52(61.2)$ & $33(38.8)$ & \multirow{2}{*}{-0.11 to 0.14} & \multirow{2}{*}{0.86} \\
\hline No & 155 & $18.2(7.2)$ & $93(60.0)$ & $62(40.0)$ & & \\
\hline \multicolumn{7}{|l|}{ Patient support group } \\
\hline No & 190 & $18.6(7.9)$ & $107(56.3)$ & $83(43.7)$ & 0.06 to 0.33 & $<0.01$ \\
\hline \multicolumn{7}{|l|}{ Glycaemic control } \\
\hline Poor $(\mathrm{HbA} 1 \mathrm{c}>7 \%)$ & 176 & $19.0(7.9)$ & $108(61.4)$ & $68(38.6)$ & \multirow{2}{*}{-0.10 to 0.18} & \multirow{2}{*}{0.62} \\
\hline Good $(\mathrm{Hb} 1 \mathrm{c} \mathrm{c} \leq 7 \%)$ & 64 & $18.4(7.6)$ & $37(57.5)$ & $27(42.4)$ & & \\
\hline
\end{tabular}

$\mathrm{Cl}$, Confidence interval; s.d., standard deviation. 
TABLE 4: Baseline characteristics of study population analysed against glycaemic control.

\begin{tabular}{|c|c|c|c|c|c|}
\hline Categorical grouping variables & Total $(N=261)$ & Good control HbA1c $\leq 7 \% N(\%)$ & Poor control HbA1c $>7 \% N(\%)$ & $95 \% \mathrm{Cl}$ & $p$ \\
\hline \multicolumn{6}{|l|}{ Sex } \\
\hline Female & 147 & $45(30.6)$ & $102(69.4)$ & & \\
\hline Male & 114 & $26(22.8)$ & $88(77.2)$ & -0.33 to 0.19 & 0.15 \\
\hline \multicolumn{6}{|l|}{ Educational level } \\
\hline Primary or less & 112 & $38(33.9)$ & $74(66.1)$ & & \\
\hline Secondary or more & 149 & $33(22.1)$ & $116(77.9)$ & $<-0.01$ to 0.22 & 0.04 \\
\hline Employed & 117 & $26(22.2)$ & $91(77.8)$ & & \\
\hline Unemployed & 144 & $45(31.3)$ & $99(68.7)$ & -0.02 to 0.20 & 0.10 \\
\hline \multicolumn{6}{|l|}{ Insulin use } \\
\hline Yes & 96 & $14(14.6)$ & $82(85.4)$ & & \\
\hline No & 165 & $57(34.5)$ & $108(65.5)$ & 0.09 to 0.30 & $<0.01$ \\
\hline \multicolumn{6}{|l|}{ Patient support group } \\
\hline Yes & 53 & $16(30.2)$ & $37(69.8)$ & & \\
\hline
\end{tabular}

$\mathrm{Cl}$, Confidence interval.

patient support group had poorer glycaemic control (73.6\%), compared to those who did attend a patient support group $(69.8 \%, p=0.09)$ (see Table 4).

\section{Discussion}

The results of the secondary data analysis found that over $60.0 \%$ of study participants reported clinically significant depressive symptoms (CES-D > 16) and over $70.0 \%$ of participants were reported as having poor glycaemic control at baseline. The study participants were not assessed for a criterion-based mood episode, but it is likely that at least some of these participants would be suffering from a mood episode.

The prevalence of depressive symptoms in this study was higher than that seen in diabetic patients in other low- and middle-income countries such as Jordan $(19.7 \%)$, Thailand ( 25\%), India $(16.9 \%-43.4 \%)$ and Guinea $(34.4 \%) .{ }^{18,33,34,35,36,37}$ However, many of these studies differ in the scale and score used to identify depression and the presence of depressive symptoms.

The presence of clinically significant depressive symptoms was found to have a significant association with gender. Women reported higher levels of clinically significant depressive symptoms compared to men. This is similar to results found in other studies surrounding depression in patients with diabetes. $35,38,39,40,41$ Our analysis suggests a significant association between depression and having a lower educational level and being unemployed; however, this was not statistically significant as has been demonstrated in other research. ${ }^{35,42,43,44,45}$

Our study found a weak positive correlation between CES-D score and glycaemic control that was not statistically significant. However, research from various countries suggests a significant association. , $36,37,38,41,42,45,46$ Despite much research, the exact direction of the relationship is as yet unknown. ${ }^{47}$ Some studies suggest that depression may be a consequence of living with diabetes mellitus because of factors such as the burden of chronic disease or the biochemical changes that occur in diabetes. ${ }^{48}$ Other studies have proposed that depressive symptoms may be a risk factor for developing diabetes mellitus because of a decline in health maintenance behaviours or biochemical changes associated with depression. ${ }^{49}$

The results of the study also found that individuals who were involved in a patient group had higher levels of clinically depressive symptoms compared to those who were not. These individuals were also found to have better glycaemic control, although this was not significant. This research suggests that individuals experiencing depressive symptoms may be more likely to engage in patient support groups. These groups can be beneficial in providing patients with valuable information, which could lead to better glycaemic control.

\section{Study strengths}

This study is one of the first to date to assess the relationship between depression and glycaemic control in Cameroon. Data were obtained from a diverse range of participants involving six diabetic care populations across Cameroon from the 'Improving access to $\mathrm{HbA1c}$ measurement in sub-Saharan Africa' study. This makes the data more representative of the population in Cameroon.

\section{Limitations}

A limitation to this study is that a self-report measure was used to assess depressive symptomology. This could explain the higher rates of depressive symptoms in the population as self-report measures often lead to higher rates of depression compared to methods using formal psychiatric interviews. ${ }^{50}$ In this study, CES-D scored > 16 were used to demonstrate clinically significant depressive symptoms. However, some studies have used recommended cut-off points of 16-23 as having 'distressed symptoms' and $>23$ as being 'depressed' ${ }^{25}$ CES-D scores using cut-off points between 21 and 23 have been shown to have a sensitivity and specificity greater than $85 \%$. ${ }^{51,46}$ 
The CES-D scale has also not yet been validated for use in Cameroon but has been widely used and validated for research in patient populations in various sub-Saharan African nations.

\section{Conclusion}

The established increase in diabetes mellitus in low- and middle-income countries indicates the need for further research. In particular, the association between depressive symptoms and glycaemic control should be explored to allow close monitoring of $\mathrm{HbA} 1 \mathrm{c}$ in individuals most at risk. The finding from this piece of research highlights the need for increased monitoring of $\mathrm{HbA1c}$ levels and detection of depressive symptoms, which might be consequent to a mood disorder. This should be achieved through appropriate and valid assessment by healthcare professionals, particularly in high-risk groups such as women, the unemployed, those with lower levels of education and those using insulin. It also suggests that patient support groups in low- and middleincome countries could help those most at risk of depressive symptoms and encourage education on how to maintain better glycaemic control.

\section{Acknowledgements}

This project is supported by a BRIDGES Grant from the International Diabetes Federation. BRIDGES, an International Diabetes Federation project, is supported by an educational grant from Lilly Diabetes.

\section{Competing interests}

The authors declare that they have no financial or personal relationships which may have inappropriately influenced them in writing this article.

\section{Authors' contributions}

K.K.H. conducted the secondary data analysis and drafted the manuscript. L.P. contributed to the data interpretation and contributed to the draft of the manuscript. J.T. and A.C. participated in the study design and co-ordination. N.M.B. and E.S. conceived of the original study concept.

\section{References}

1. World Health Organization Media Centre, WHO. World Health Organization media centre [homepage on the Internet]. [cited $2013 \mathrm{Jul}$. Available from: http://www. who.int/mediacentre/factsheets/fs312/en/

2. Mbanya JCN, Motala AA, Sobngwi E, Assah FK, Enoru ST. Diabetes in sub-Saharan Africa. Lancet. 2010;375(9733):2254-2266. https://doi.org/10.1016/S0140-6736 (10)60550-8

3. Gill GV, Mbanya JC, Ramaiya KL, Tetaye S. A sub-Saharan African perspective of diabetes. Diabetologica. 2009;52(1):8-16. https://doi.org/10.1007/s00125-008$1167-9$

4. World Health Organization (WHO). Depression Factsheet [homepage on the Internet]. [cited 2013 Jun]. Available from: http://www.who.int/mediacentre/ factsheets/fs369/en/

5. Katon WJ, Fan MY, Unutzer J, Taylor J, Pincus H, Schoenbaum M. Depression and diabetes: A potentially lethal combination. J Gen Intern Med. 2008;23(10): 1571-1575. https://doi.org/10.1007/s11606-008-0731-9

6. Katon WJ, Rutter C, Simon G. The association between comorbid depression with mortality in patients with type 2 diabetes. Diabetes Care. 2005;28(11): 2668-2672. https://doi.org/10.2337/diacare.28.11.2668
7. Black SA, Markides KS, Ray LA. Depression predicts increased incidence of adverse health outcomes in older Mexican Americans with type 2 diabetes. Diabetes Care. 2003;26(10):2822-2828. https://doi.org/10.2337/diacare.26.10.2822

8. Lin EH, Heckbert SR, Rutter CM. Depression and increased mortality in diabetes: Unexpected causes of death. Ann Fam Med. 2009;7(5):414-421. https://doi. org/10.1370/afm.998

9. Anderson RJ, Freedland KE, Clouse RE, Lustman PJ. The prevalence of comorbid depression in adults with diabetes: A meta-analysis. Diabetes Care. 2001; 24(6):1069-1078. https://doi.org/10.2337/diacare.24.6.1069

10. De groot $M$, Anderson R, Freedland KE. Association of depression and diabetes complications: A meta-analysis. Psychosom Med. 2001;63(4):619-630. https:// doi.org/0033-3174/01/6304-0619

11. Olafsdottir E, Andersson DK, Stefansson E. Visual acuity in a population with regular screening for type 2 diabetes mellitus and eye disease. Acta Ophthalmo Scand. 2007;85(1):40-45. https://doi.org/10.1111/j.1600-0420.2006.00753

12. Motala AA. Microalbuminuria in diabetes mellitus - Significance and screening. S Afr Med J. 1998;88(3):365-366.

13. Lund C, Myer L, Stein DJ, Williams DR, Flisher AJ. Mental illness and lost income among adult South Africans. Soc Psychiatry Psychiatr Epidemiol. 2013;48(5): 845-851. https://doi.org/10.1007/s00127-012-0587-5

14. Mendenhall E, Norris SA, Shidhaye R, Prabhakaran D. Depression and type 2 diabetes in low and middle income countries: A systematic review. Diabetes Res Clin Pract. 2014:103(2):276-285. https://doi.org/10.1016/j.diabres.2014.01.001

15. Tomlinson M, Swartz L, Kruger LM, Gureje $O$. Manifestations of affective disturbance in sub-Saharan Africa: Key themes. J Affect Disord. 2007; 102(1-3):191-198. https://doi.org/10.1016/j.jad.2006.09.029

16. Hamad R, Fernald LC, Karlan DS, Zinman J. Social and economic correlates of depressive symptoms and perceived stress in South African adults. J Epidemio Community Health. 2008;62(6):538-544. https://doi.org/10.1136/jech.2007.066191

17. Jegede RO. Depression in Africans revisited: A critical review of the literature. Afr J Med Med Sci. 1979;8(3-4):125-132.

18. Kagee A. Symptoms of depression and anxiety among a sample of South African patients living with a chronic illness. J Health Psychol. 2008;13(4):547-555. https://doi.org/10.1177/1359105308088527

19. Camara A. Prevalence of anxiety and depression among diabetic African patients in Guinea: Association with HbA1c levels. Diabetes Metab. 2015;41(1):62-68. https://doi.org/10.1016/j.diabet.2014.04.007

20. Roy T, Lloyd CE, Parvin M. Prevalence of co-morbid depression in out-patients with type 2 diabetes mellitus in Bangladesh. BMC Psychiatry. 2012;12(123):1-10.

21. Bringing research in diabetes to global environments and systems, BRIDGES Improving access to HbA1c measurements in sub-Saharan Africa (LTO7-135) [homepage on the Internet]. [cited 2013]. Available from: http://www.idf.org/ BRIDGES/supported-projects/long-term-1st-round/LT-07-135

22. Sobngwi E, Balde N. Translating evidence into practice: Improving access to HbA1c in sub-Saharan Africa. Diabetes Voice [serial online]. 2011;46(1):36-39. Available from: http://www.idf.org/translating-evidence-practice-improving-access-hba1csub-saharan-africa

23. National Eye Institute (NEI). US National Institutes of Health [homepage on the Internet]. [cited 2013 Jun]. Available from: https://clinicaltrials.gov/ct2/show/ NCT00000151

24. Radloff LS. The CES-D Scale: A self-report depression scale for research in the general population. Appl Psych Meas. 1977;1(3):385-401. https://doi.org/ 10.1177/014662167700100306

25. Kaharuza FM, Bunnell R, Moss S, et al. Depression and CD4 cell count among persons with HIV infection in Uganda. AIDS Behav. 2006:10 (4 Suppl):S105-S111. https://doi.org/10.1007/s10461-006-9142-2

26. Farley J, Miller E, Zamani A, et al. Screening for hazardous alcohol use and depressive symptomatology among HIV-infected patients in Nigeria: Prevalence, predictors, and association with adherence. J Int Assoc Physicians AIDS Care. 2010;9(4):218-226. https://doi.org/10.1177/1545109710371133

27. Troeman ZC, Spies G, Cherner M, et al. Impact of childhood trauma on functionality and quality of life in HIV-infected women. Health Qual Life Outcomes. 2011:9:84. https://doi.org/10.1186/1477-7525-9-84

28. Nakasujja N, Skolasky RL, Musisi S, et al. Depression symptoms and cognitive function among individuals with advanced HIV infection initiating HAART in Uganda. BMC Psychiatry. 2010;10(44):1-7. https://doi.org/10.1186/1471-244X-10-44

29. Chishinga N, Kinyanda E, Weiss HA, et al. Validation of brief screening tools for depressive and alcohol use disorders among TB and HIV patients in primary care in Zambia. BMC Psychiatry. 2011;11(75):1-10. https://doi.org/10.1186/1471 244X-11-75

30. IBM Corp [computer software]. IBM SPSS Statistics for Windows ${ }^{\oplus}$, Version 19.0 Armonk, NY: IBM Corp; 2010.

31. Minitab $16 \circledast$ Statistical Software [computer software]. State College, PA: Minitab; 2010. Available from: http://www.minitab.com

32. Epi Info ${ }^{\mathrm{TM}} 7$ Statistical Software [Computer software]. Atlanta, GA: Centers for Disease Control and Prevention. Available from: http://www.cdc.gov/epiinfo/ index.html

33. Thaneerat T, Tangwongchai S, Worakul P. Prevalence of depression, hemoglobin A1C level, and associated factors in outpatients with type-2 diabetes. Asian Biomed. 2009;3(4):383-390. https://doi.org/10.5372/abm.v3i4.234

34. Al-amer RM, Sobeh MM, Zayed AA, Al-Domi HA. Depression among adults with diabetes in Jordan: Risk factors and relationship to blood sugar control. J Diabetes Complications. 2011;25(4):247-252. https://doi.org/10.1016/j.jdiacomp.2011.03.001 
35. Balhara YP, Sagar R. Correlates of anxiety and depression among patients with type 2 diabetes mellitus. Indian J Endocrinol Metab. 2011:15(Suppl 1):S50-S54. https://doi.org/10.4103/2230-8210.83057

36. Bajaj S, Agarwal SK, Varma A. Association of depression and its relation with complications in newly diagnosed type 2 diabetes. Indian J Endocrinol Metab. 2012;16(5):759-763. https://doi.org/10.4103/2230-8210.100670

37. Mathew CS, Dominic M, Issac R, Jacob JJ. Prevalence of depression in consecutive patients with type 2 diabetes mellitus of 5 -year duration and its impact on glycaemic control. Indian J Endocrinol Metab. 2012;16(5):764-768. https://doi. org/10.4103/2230-8210.100671

38. Egede LE, Zheng D, Simpson K. Comorbid depression is associated with increased health care and expenditures in individuals with diabetes. Diabetes Care. 2002;25(3):464-470. https://doi.org/10.2337/diacare.25.3.464

39. Sweileh WM, Abu-hadeed HM, Al-jabi SW, Zyoud SH. Prevalence of depression among people with type 2 diabetes mellitus: A cross-sectional study in Palestine. BMC Public Health. 2014;14(163):1-11. https://doi.org/10.1186/1471-245814-163

40. Zuberi SI, Syed EU, Bhatti JA. Association of depression with treatment outcomes in type 2 diabetes mellitus patients: A cross-sectional study from Karachi, Pakistan. BMC Psychiatry. 2011;11(77):1-6. https://doi.org/10.1186/ 1471-244X-11-27

41. Katon W, Russo J, Lin EH. Depression and diabetes: Factors associated with major depression at five-year follow-up. Psychosomatics. 2009;50(6):570-579. https:// doi.org/10.1176/appi.psy.50.6.570

42. Miyaoka Y, Miyaoka H, Motomiya T, Kitamura S, Asai M. Impact of sociodemographic and diabetes-related characteristics on depressive state among non-insulin dependent diabetic patients. Psychiatry Clin Neurosci. 1997;51(4):203-206. https://doi.org/10.1111/j.1440-1819.1997.tb02583.x
43. Roy A, Roy M. Depressive symptoms in African-Americans with type 1 diabetes Depress Anxiety. 2001;13(1):28-31. https://doi.org/10.1002/1520-6394(2001) 13:1<28::AID-DA4>3.0.CO;2-G

44. Pouwer F, Geelhoed-duijvestijin PH, Tack CJ, et al. Prevalence of comorbid depression is high in out-patients with type-1 diabetes or type-2 diabetes mellitus. Results from three out-patient clinics in the Netherlands. Diabet Med. 2010; 27(2):217-224. https://doi.org/10.1111/j.1464-5491.2009.02903.x

45. Ciechanowski PS, Hirsch B, Katon WJ. Interpersonal predictors of HbA1c in patients with type 1 diabetes. Diabetes Care. 2002;25(4):731-736. https://doi org/10.2337/diacare.25.4.731

46. Fava GA, Pilowsky I, Pierfederici A. Depression and illness behaviour in a general hospital: A prevalence study. Psychother Psychosom. 1982;38(1-4):141-153. https://doi.org/10.1159/000287622

47. Lustman PJ, Clouse RE. Depression in diabetes: The chicken or the egg? Psychosom Med. 2007;69(4):297-299. https://doi.org/10.1097/PSY.0b013e318060cc2d

48. Knol MJ, Heerdink ER, Egberts AC. Depressive symptoms in subjects with diagnosed and undiagnosed type 2 diabetes. Psychosom Med. 2007;69(4): 300-305. https://doi.org/10.1097/PSY.0b013e31805f48b9

49. Golden SH. A review of the evidence for a neuroendocrine link between stress, depression and diabetes mellitus. Curr Diabetes Rev. 2007;3(4):252-259. https:// doi.org/10.2174/157339907782330021

50. Lustman PJ, Anderson RJ, Freedland KE, de Groot M, Carney RM, Clouse RE. Depression and poor glycaemic control: A meta-analytic review of the literature. Diabetes Care. 2000;23(7):934-942. https://doi.org/10.2337/diacare.23.7.934

51. Lyness JM, Noel TK, Cox C, King DA, Conwell Y, Caine ED. Screening for depression in elderly primary care patients. A comparison of the center for epidemiologic studies - Depression scale and the geriatric depression scale. Arch Intern Med. 1997;157(4):449-454. https://doi.org/10.1001/archinte.1997.00440250107012 